\title{
Chemopreventive alteration of the cell-cell adhesion in head and neck squamous cell cancer
}

\author{
RAMIN NAIM ${ }^{1}$, RAY C. CHANG ${ }^{2}$, JOHANNES SCHULTZ ${ }^{1}$ and KARL HORMANN ${ }^{1}$ \\ ${ }^{1}$ Department of Otolaryngology, Head and Neck Surgery, University Hospital Mannheim, Germany; \\ ${ }^{2}$ Department of Otolaryngology, University of Miami/Jackson Memorial Hospital, Miami, FL, USA
}

Received January 4, 2006; Accepted March 30, 2006

\begin{abstract}
Approximately 310,000 new cases of oral and pharynx cancer account for a major cause of neoplasm related morbidity and mortality world-wide. Unfortunately, the survival rate has not improved significantly in the last decade. The vast majority of head and neck cancer is squamous cell carcinoma. The major adhesion-proteins involved in the development and maintenance of all solid tissue are the Cadherins. Cadherins are the transmembrane components of the adherent junction with interaction with plakoglobin and $\beta$-catenin. Downregulation of Cadherins and catenins is frequently observed in many types of human cancer. Sulindac sulfone is one of the new therapeutic apoptotic agents that show promise in the treatment of cancer. In this study, we incubated sulindac sulfone with a head and neck cancer cell line and investigated the outcome of E-Cadherin. Immunohistochemical and Western blot analyses were then performed, with different concentrations of sulindac sulfone (100, 200, 400,600 , and $800 \mu \mathrm{Mol}$ ) for $48 \mathrm{~h}$. At $400 \mu \mathrm{Mol}$ of sulindac sulfone a decrease of $21 \%$ was observed; at $600 \mu \mathrm{Mol}, 44 \%$ decrease of $B$-catenin concentration was seen, and incubation with $800 \mu \mathrm{Mol}$ resulted in $73 \%$ reduction of secreted $\beta$-catenin. Incubation with sulindac sulfone seemed to stop proliferation; however, with respect to the controls, there was no increased reduction of the total protein. Sulindac sulfone resulted in an increase of E-Cadherin content in the head and neck squamous cell cancer cell line after $48 \mathrm{~h}$ of incubation; however, the reactivity was restricted to the adherent junctions. At increasing concentrations of sulindac sulfone, intercellular E-Cadherin immunostaining intensifyied. ELISA also depicted significant rising levels of E-Cadherin. Sulindac sulfone contributes to the inactivation of cGMP phospho-diesterase. Thus, the accumulation of cellular cGMP and protein kinase $\mathrm{G}$ is induced. The
\end{abstract}

Correspondence to: Dr Ramin Naim, University-HNO-Klinik Theodor-Kutzer-Ufer, 68135 Mannheim, Germany

E-mail: ramin.naim@hno.ma.uni-heidelberg.de

Key words: E-Cadherin, head and neck squamous cell cancer, sulindac sulfone, chemoprevention following degradation of the phosphorylated $\beta$-catenin and the dissociation from the Cadherin-catenin complex releases E-Cadherin. This may also contribute to growth inhibition and co-ordinate with apoptosis induction. It is not really clear as to, which pathway results in the elevation of the E-Cadherin proteins. However, in epithelial cancer cells, the Cadherincatenin complex serves as a target for the chemopreventive agent, sulindac sulfone.

\section{Introduction}

Head and neck squamous cell cancer (HNSCC). Approximately 310,000 new cases of oral and pharynx cancer account for a major cause of neoplasm related morbidity and mortality world-wide (1). In the United States, the 40,100 new cases and around 12,000 cancer deaths caused by head and neck cancer annually, are evidence for a serious public health problem (2). Unfortunately, the survival rate has not improved significantly in the last decades (3). The development of recurrence and metastasis plus the incidence of second primary tumors result in the poor survival rate (3). It has been postulated that head and neck cancer are the result of the amassing of genetic and tissue damage caused by carcinogens (4). The management of the disease requires multimodal therapy including surgery, chemoradiation or the combination of these treatment strategies (3). The vast majority of head and neck cancer is squamous cell carcinoma (HNSCC) (1).

E-Cadherin. Cell-cell adhesion is established by different types of molecules. The major proteins involved in the development and maintenance of all solid tissue are Cadherins (5). Cadherins are the transmembrane components of the adherent junction with interaction with plakoglobin and $B$ catenin. Within the Cadherins, E-Cadherin is found in the polarized epithelial cell junctions (6). Most of the dynamic adhesive interactions between cells are regulated by the Cadherins and catenins (7). Intracellularly, the activation of the Rho family GTPase and the function of tyrosine kinase signalling are modulated by the Cadherins (6). The inside-out signalling is determined by the GTPase to the Cadherins and outside-in signalling is initiated by the Cadherins (8). Steinberg and Takeichi reported that the level of Cadherin expression influences the strength of adhesion between the cells of different types of tissue (9). Cell adhesion and the 
state of adherent junctions, which is established by the Cadherins, can be affected by many different cellular processes, e.g. by growth factors or apoptotic factors. Downregulation of Cadherins and catenins is frequently observed in many types of human cancer (10).

Sulindac sulfone. Sulindac sulfone is one of the new therapeutic apoptotic agents that show promise in the treatment of cancer. The development of this agent demonstrated that it had a new mechanism of action involving the induction of apoptosis selectively in precancerous and malignant tissue (11). A new category of targeted anti-cancer agents has been introduced: selective apoptotic antineoplastic drugs (SAANDs) (11). Different mechanisms that activate protein kinase $\mathrm{G}$ (PKG) lead to multiple downstream effects that cumulate in programmed cell death or apoptosis. Sulindac sulfone increases the cellular concentration of cGMP and, thus, activation of PKG is induced (12).

In previous experiments, we reported that, in different head and neck cancer cell lines, B-catenin was degraded by sulindac sulfone (Naim et al, unpublished data). Different authors reported that the degradation of $\beta$-catenin and the activation of JUN kinase (JNK) trigger apoptosis by different routes (11-13). In this study, we incubated sulindac sulfone with the head and neck cancer cell line, 14C, and investigated the outcome of E-Cadherin by means of ELISA and immunohistochemistry.

\section{Materials and methods}

Cell culture. The different UMSCC cell lines are welldescribed human HNSCC cell lines obtained from Dr TE. Carey (The University of Michigan, Ann Arbor, Michigan, USA). Cell cultures were carried out in Falcon petri dishes at $37^{\circ} \mathrm{C}$ in a $5 \% \mathrm{CO}_{2}$ fully humidified atmosphere using Dulbecco's modified minimum essential medium (DMEM) (Fisher Scientific Co., Pittsburgh, PA, USA) supplemented with $10 \%$ fetal calf serum (FCS) and antibiotics [Life Technologies, Inc. (Gibco BRL), Gaithersburg, MD, USA].

Characterisation of the cell lines (immunohistochemistry). Immunohistochemical analysis was performed using a monoclonal mouse anti-human antibody directed against B-catenin (E-Cadherin: C19220, Transduction Laboratories, Lexington, KY). Immunostaining was performed using the alkalinephosphatase-anti-alkaline phosphatase method (APAAP). Four- $\mu \mathrm{m}$ sections were cut consecutively from formalinfixed and paraffin-embedded tissue samples, mounted on poly-L-lysin coated slides and dried overnight at $37^{\circ} \mathrm{C}$. Paraffin sections were dewaxed by xylene, rehydrated with graded concentrations of ethanol, and finally washed in Trisbuffer ( $\mathrm{pH} \mathrm{7.2)} \mathrm{for} 10 \mathrm{~min}$. A microwave pre-treatment was required for $15 \mathrm{~min}$ at $600 \mathrm{~W}$ using citrate buffer for ECadherin. An automated staining system, Dako TechMate 500 (Dako, Hamburg, Germany), was used for the final steps. Sections were incubated with the primary antibody solution for $25 \mathrm{~min}$ at room temperature, using a working dilution of the antibody 1:300 for E-Cadherin. Slides were rinsed once in buffer (Buffer kit, Dako). Immunoreaction was demonstrated with the Dako ChemMate detection kit (APAAP, mouse, code no. K5000, Dako), according to the manufacturer's instructions. Sections were incubated with the chromogen alkalinephosphatase substrate (Neufuchsin, Dako) for $20 \mathrm{~min}$ at room temperature. Finally, sections were counterstained by Mayer's-hematoxylin for $3 \mathrm{~min}$, dehydrated in graded ethanol, and coverslipped. Negative controls used all reagents except the primary antibody.

The results of the immunohistochemically obtained rates of expression were analysed semiquantitatively. The stain intensity was noted as follows: strong reactivity, $>80 \%$ of the epithelium cells were positive; moderate reactivity, 50-80\% reactive; weak reactivity, $<50 \%$ reactive; and no positive cells. Western blot analysis was performed as described by Knipp et al (14).

E-Cadherin-ELISA principle. Secreted E-Cadherin was measured in the supernatant of the cell lines using an ELISA technique (R\&D Systems, Wiesbaden, Germany). Cell culture supernatants were collected in sterile test tubes and stored at $-20^{\circ} \mathrm{C}$ until used. Then, E-Cadherin concentrations were determined by ELISA (R\&D Systems). The system used a solid-phase monoclonal antibody and an enzyme-linked polyclonal antibody raised against E-Cadherin. The specificity of anti-human E-Cadherin antibodies used in the ELISA kit were examined by sodium dodecylsulphate polyacrylamide gel electrophoresis (SDS-PAGE) followed by Western blotting. According to the manufacturer's instructions, $100 \mu 1$ of supernatant were used for each ELISA assay. All analyses and calibrations were carried out in duplicate. The calibrations on each microtiter plate included E-Cadherin standards provided in the kit. Optical density was determined using a microplate reader at a wavelength of $450 \mathrm{~nm}$. Wavelength correction was set to $540 \mathrm{~nm}$ and concentrations were reported as $\mu \mathrm{g} / \mathrm{ml}$. After 8,24 , and 48 h of incubation with $0,100,200,400,600$, and $800 \mu \mathrm{Mol}$ sulindac sulfone, the expression of the E-Cadherin protein in the supernants of the treated and untreated culture cells was analyzed. Controls were performed using DMS without sulindac sulfone during incubation.

\section{Results}

Immunohistochemistry. The immunohistochemical studies against E-Cadherin showed increased reactivity with rising concentrations of sulindac sulfone. The controls showed less reactivity. The immunostaining was localized in the mural parts of the cells (Fig. 1A-D).

Eight, 24, and 48 of incubation with sulindac sulfone. ECadherin levels were at $0.000371 \mu \mathrm{g} / \mathrm{ml}$ after $8 \mathrm{~h}$ of incubation with $100 \mu \mathrm{Mol}$ sulindac sulfone. After $48 \mathrm{~h}$, the average level of E-Cadherin was measured at $0.000427 \mu \mathrm{g} /$ $\mathrm{ml}$. This showed an increase of $13.11 \%$. Sulindac sulfone (200 $\mu \mathrm{Mol}$ ) resulted in an increase of $16.41 \%$, and $400 \mu \mathrm{Mol}$ showed $21.17 \%$ raising of E-Cadherin. After $48 \mathrm{~h}$, treated cells with 600 and $800 \mu \mathrm{Mol}$ sulindac sulfone expressed $29.51 \%$ and $32.22 \%$ increase of E-Cadherin, respectively (Fig. 4C).

The total protein content decreased by $\sim 9.85 \%$ after $48 \mathrm{~h}$ of incubation with $100 \mu \mathrm{Mol}$ sulindac sulfone. Sulindac sulfone $(800 \mu \mathrm{Mol})$ resulted in a decrease of the total protein 

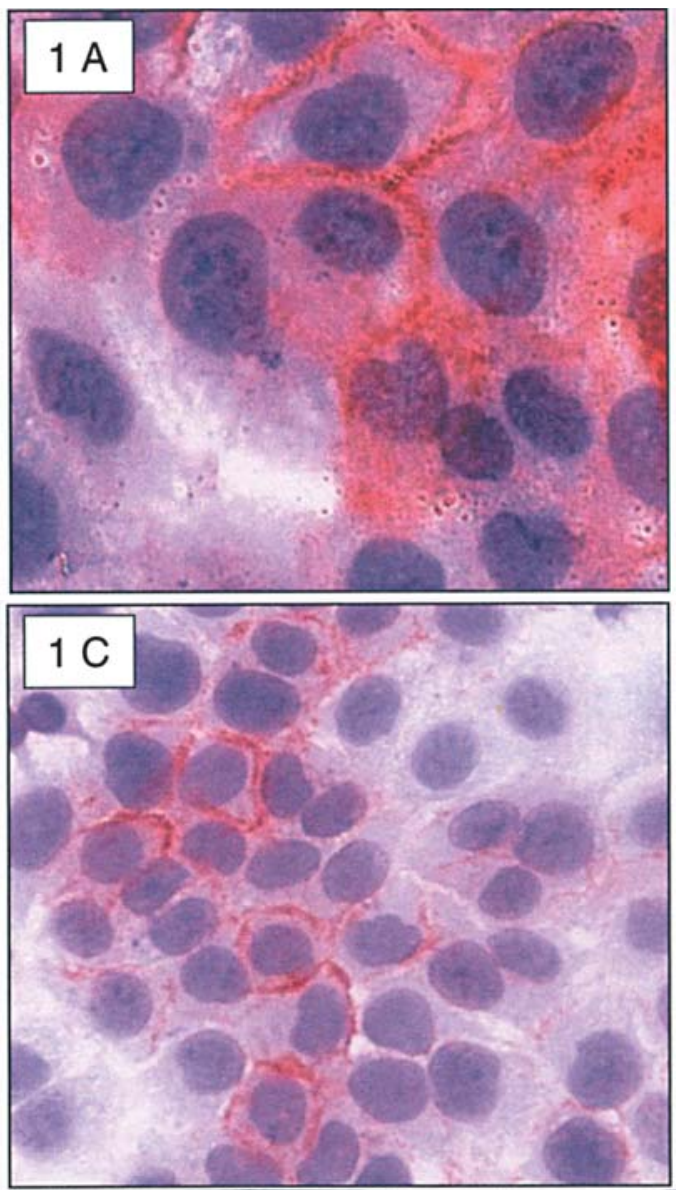

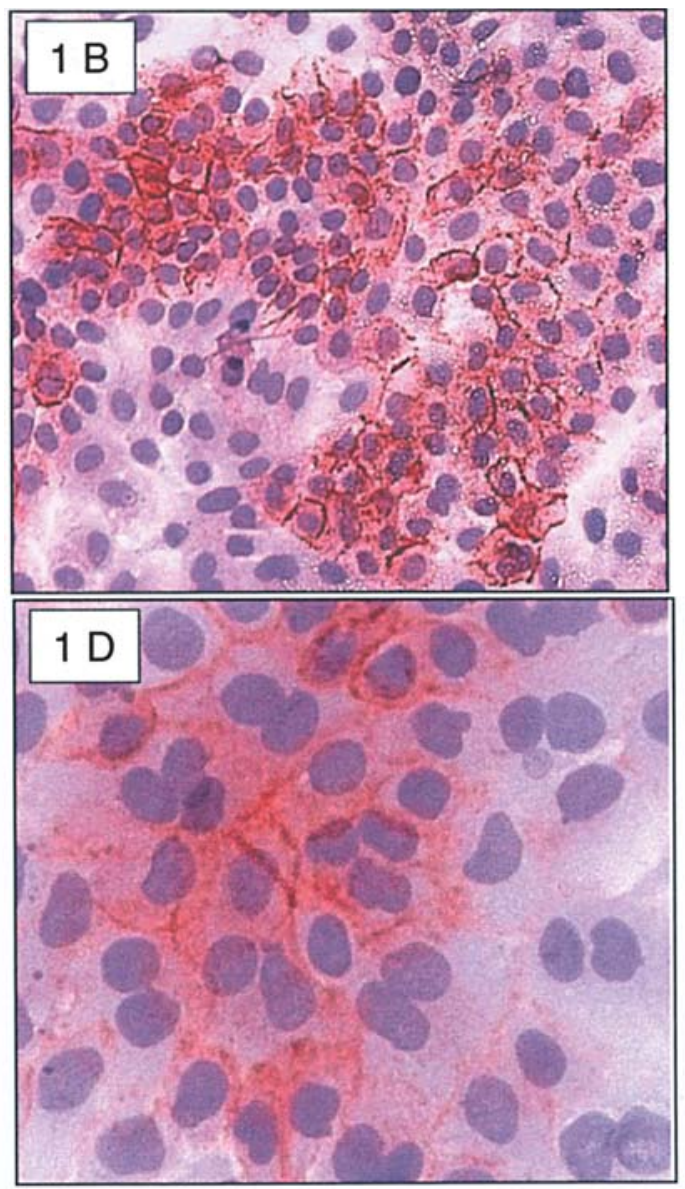

Figure 1. (A,B) Positive immunohistochemical reactivity against E-Cadherin (X40 and X20) after incubation with $600 \mu$ Mol sulindac sulfone for 48 h, (C) faint reactivity against E-Cadherin (X40; $100 \mu \mathrm{Mol}$ sulindac sulfone for $48 \mathrm{~h}$ ), (D)

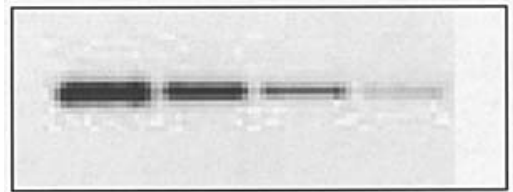

Figure 2. Western blot analysis for E-Cadherin.

content by $44.09 \%$ (Fig. $4 \mathrm{~A}$ and B). In regard to the total protein levels, E-Cadherin increased after incubation with $100 \mu \mathrm{Mol}$ sulindac sulfone by $\sim 29.41 \%$. Incubation for $48 \mathrm{~h}$ with $800 \mu \mathrm{Mol}$ sulindac sulfone resulted in an increase of $36.51 \%$ (regarding total protein content). These results were significant $(\mathrm{p}<0.05)$ (Fig. 4D).

Western blot analysis for E-Cadherin after incubation with sulindac sulfone verified the increase of the E-Cadherin content in the UM-SCC 14C cell line (Fig. 2).

\section{Discussion}

In different tissues, Cadherins form a calcium dependent cellcell-adhesion complex called adherent junction. Different authors reported that the expression of E-Cadherin was reduced in several epithelial tumors $(3,4,15)$. It was stated that cancer cells that have infiltrated the stroma, reduced the expression of E-Cadherin and accumulated B-catenin (15). In

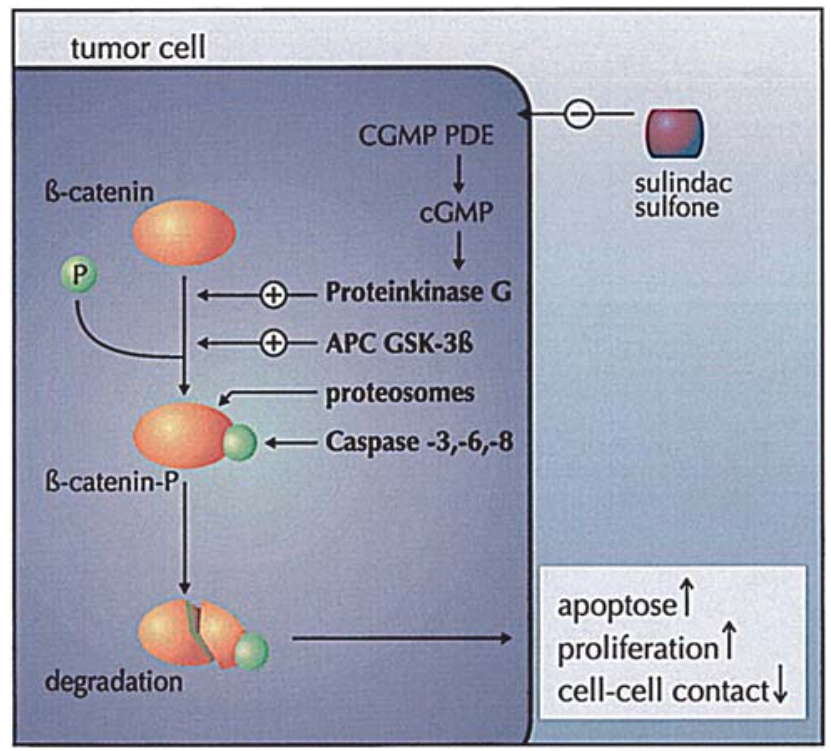

Figure 3. Different mechanisms for the degradation of $\beta$-catenin resulting in apoptosis.

breast, stomach, and prostate carcinomas, the reduced expression of E-Cadherin was associated with high frequency of metastasis and poor prognosis $(3,4)$. However, in ovarian cancer development, Reddy et al showed that E-Cadherin 
A

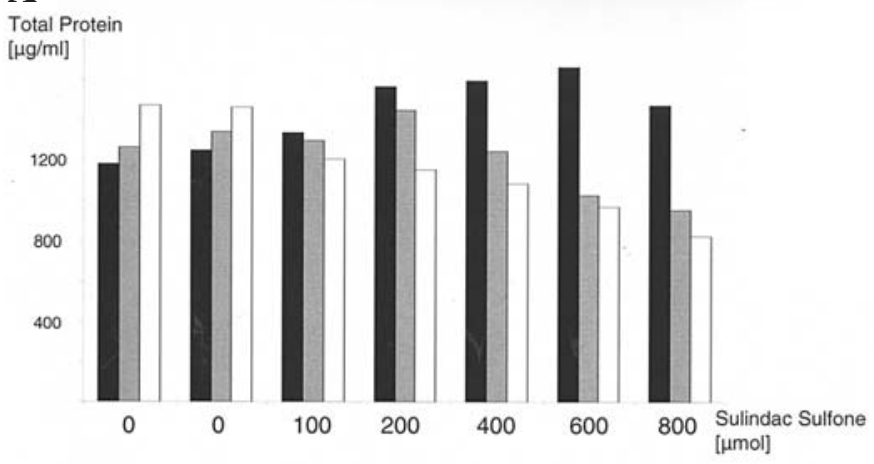

B

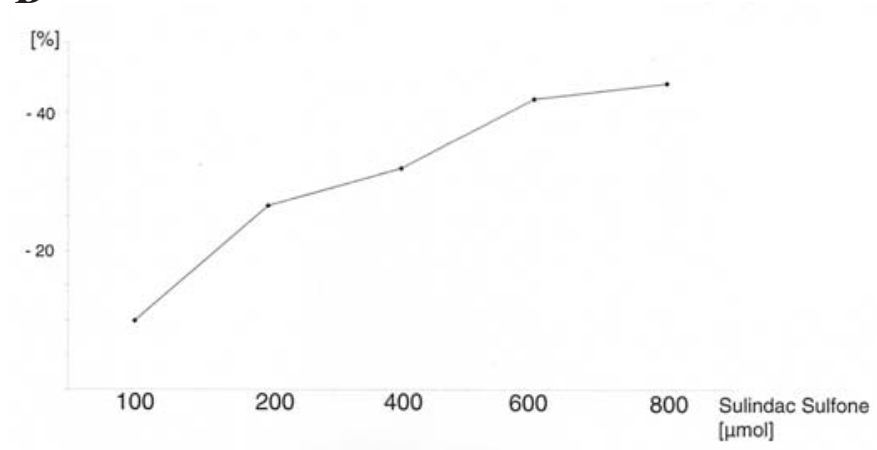

C

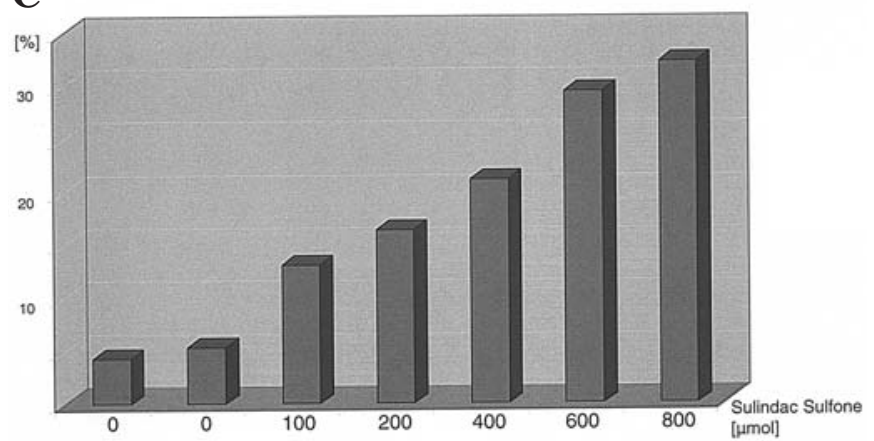

D

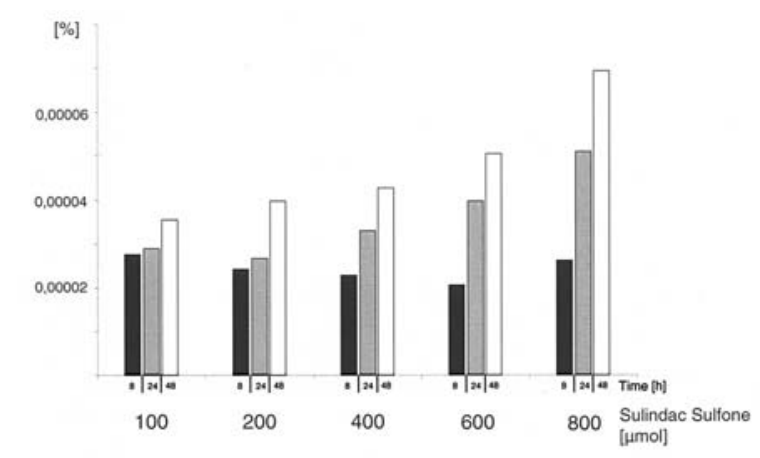

Figure 4. (A) Content of the total protein after incubation with sulindac sulfone, (B) percental decrease of the total protein after incubation with sulindac sulfone $[\mu \mathrm{mol}]$, (C) increase of E-Cadherin levels after incubation with sulindac sulfone, (D) percentage of E-Cadherin in regard of the total protein after incubation with sulindac sulfone.

expression was uniquely elevated in $86.5 \%$ of benign, borderline, and malignant ovarian carcinomas irrespective of the degree of differentiation, whereas normal ovarian samples did not express E-Cadherin (16). Bulkholm et al also showed 're-expression' of E-Cadherin in breast cancer metastasis; they deduced that this was most likely necessary for the tumor cells' capacity of attaching themselves to other organs (17), but the mechanism involved in this process is still unclear.

In our experiment we illustrated that in the untreated cells (controls) of the cancer cell line, 14C, the immunohistochemical reactivity against E-Cadherin was faint to moderate. The immunostaining was localized at the cellular membrane and no intracellular reactivity was detected. The incubated cells showed remarkable increased expression of E-Cadherin, however, the reactivity was restricted to the adherent junctions. At increasing concentrations of sulindac sulfone, inter-cellular E-Cadherin immunostaining intensified (Fig. 1A-C). The ELISA also depicted significant rising levels of E-Cadherin.

Cell-cell adhesion plays a critical role in the development and maintenance of epithelial tissue integrity and function. During cancer progression, disturbance of intercellular adhesion contributes to malignant progression, invasion, and metastasis. The Cadherin-catenin interaction guarantees the integrity of tissue. The level of Cadherin expression influences the strength of adhesion. In this study, we showed that decreased levels of E-Cadherin in the cancer cell line, 14C, were elevated after treatment with different levels of sulindac sulfone, which is reported to inhibit growth and to induce apoptosis (13). Sulindac sulfone, is not an NSAID (nonsteroidal anti-inflammatory drug) because it lacks the hallmark cyclooxygenase inhibitory activities of NSAIDs (18).
Furthermore, the mechanism of sulindac sulfone-induced apoptosis is independent of Bcl-2, p53, and cell cycle arrest $(19,20)$. Sulindac sulfone contributes to the inactivation of cGMP phosphodiesterase (PDE). Thus, the accumulation of cellular cGMP and protein kinase G (PKG) is induced (21). The following degradation of the phosphory-lated $\beta$-catenin and the dissociation from the Cadherin-catenin complex releases E-Cadherin (23). The effect appears to require nonselective rather than selective PDE5 inhibitors. Other effects of the sulindac sulfone-induced PKG phosphorylation may also contribute to growth inhibition and coord-inate with apoptosis induction (24). However, it is still not totally clear as to which pathway results in the elevation of the ECadherin proteins. There has been no involvement of cGMP PDE, PKG, and E-Cadherin in one distinct pathway. The increased levels of E-Cadherin are rather the effect of the degradation of ß-catenin (Fig. 3).

In summary, this study contributes to the hypothesis that in epithelial cancer cells, the Cadherin-catenin complex serves as a target for the chemopreventive agent, sulindac sulfone. It is necessary to establish additional studies concerning the distinct molecular-biological effect of sulindac sulfone on the adherent junctions. As chemoprevention, this might be one solution for loco-regional control of head and neck cancer, which limits the survival rate of the patients.

\section{Acknowledgements}

The authors would like to thank Petra Prohaska for her excellent technical assistance. 


\section{References}

1. Franceschi S, Munoz N, Bosch XF, Snijders PJ and Walboomers JM: Human papillomavirus and cancers of the upper aerodigestive tract: a review of epidemiological and experimental evidence. Cancer Epidemiol Biomarkers Prev 5: 567-575, 1996.

2. Mashberg A: Re: Oral cavity cancer in non-users of tobacco. J Natl Cancer Inst 85: 1525, 1993.

3. Vokes EE, Weichselbaum RR, Lippman SM and Hong WK: Head and neck cancer. N Engl J Med 328: 184-194, 1993.

4. Hong WK and Sporn MB: Recent advances in chemoprevention of cancer. Science 278: 1073-1077, 1997.

5. Takeichi M, Inuzuka H, Shimamura K, Matsunaga M and Nose A: Cadherin-mediated cell-cell adhesion and neurogenesis. Neurosci Res Suppl 13: S92-S96, 1990.

6. Nollet F, Kools P and van Roy F: Phylogenetic analysis of the cadherin superfamily allows identification of six major subfamilies besides several solitary members. J Mol Biol 299: 551-572, 2000.

7. Gumbiner BM: Signal transduction of beta-catenin. Curr Opin Cell Biol 7: 634-640, 1995.

8. Fukata M and Kaibuchi K: Rho-family GTPases in cadherinmediated cell-cell adhesion. Nat Rev Mol Cell Biol 2: 887-897, 2001.

9. Steinberg MS and Takeichi M: Experimental specification of cell sorting, tissue spreading, and specific spatial patterning by quantitative differences in cadherin expression. Proc Natl Acad Sci USA 91: 206-209, 1994

10. Depondt J, Shabana AH, Florescu-Zorila S, Gehanno P and Forest N: Down-regulation of desmosomal molecules in oral and pharyngeal squamous cell carcinomas as a marker for tumour growth and distant metastasis. Eur J Oral Sci 107: 183-193, 1999

11. Thompson WJ, Piazza GA, Li H, Liu L, Fetter J, Zhu B, Sperl G, Ahnen D and Pamukcu R: Exisulind induction of apoptosis involves guanosine 3 ', 5'-cyclic monophosphate phospho-diesterase inhibition, protein kinase $\mathrm{G}$ activation, and attenuated betacatenin. Cancer Res 60: 3338-3342, 2000.

12. Soh JW, Mao Y, Liu L, Thompson WJ, Pamukcu R and Weinstein IB: Protein kinase G activates the JNK1 pathway via phosphorylation of MEKK1. J Biol Chem 276: 16406-16410, 2001.

13. Soh JW, Mao Y, Kim MG, Pamukcu R, Li H, Piazza GA, Thompson WJ and Weinstein IB: Cyclic GMP mediates apoptosis induced by sulindac derivatives via activation of c-Jun NH2terminal kinase 1. Clin Cancer Res 6: 4136-4141, 2000.
14. Knipp BS, Ailawadi G, Ford JW, Peterson DA, Eagleton MJ, Roelofs KJ, Hannawa KK, Deogracias MP, Ji B, Logsdon C, Graziano KD, Simeone DM, Thompson RW, Henke PK, Stanley JC and Upchurch GR Jr: Increased MMP-9 expression and activity by aortic smooth muscle cells after nitric oxide synthase inhibition is associated with increased nuclear factor-kappaB and activator protein-1 activity. J Surg Res 116: 70-80, 2004.

15. Hayashida $Y$, Honda $K$, Idogawa M, Ino Y, Ono M, Tsuchida A, Aoki T, Hirohashi $\mathrm{S}$ and Yamada T: E-cadherin regulates the association between beta-catenin and actinin-4. Cancer Res 65 : 8836-8845, 2005.

16. Reddy P, Liu L, Ren C, Lindgren P, Boman K, Shen Y, Lundin E, Ottander U, Rytinki M and Liu: Formation of E-cadherinmediated cell-cell adhesion activates AKT and mitogen activated protein kinase via phosphatidylinositol 3 kinase and ligandindependent activation of epidermal growth factor receptor in ovarian cancer cells Mol Endocrinol 19: 2564-2578, 2005.

17. Lippman SM, Benner SE and Hong WK: Cancer chemoprevention. J Clin Oncol 12: 851-873, 1994.

18. Drees M, Zimmermann R and Eisenbrand G: 3',5'-Cyclic nucleotide phosphodiesterase in tumor cells as potential target for tumor growth inhibition. Cancer Res 53: 3058-3061, 1993.

19. Piazza GA, Alberts DS, Hixson LJ, Paranka NS, Li H, Finn T, Bogert C, Guillen JM, Brendel K, Gross PH, Sperl G, Ritchie J, Burt RW, Ellsworth L, Ahnen DJ and Pamukcu R: Sulindac sulfone inhibits azoxymethane-induced colon carcinogenesis in rats without reducing prostaglandin levels. Cancer Res 57: 2909$2015,1997$.

20. Lim JT, Piazza GA, Han EK, Delohery TM, Li H, Finn TS, Buttyan R, Yamamoto H, Sperl GJ, Brendel K, Gross PH, Pamukcu R and Weinstein IB: Sulindac derivatives inhibit growth and induce apoptosis in human prostate cancer cell lines. Biochem Pharmacol 58: 1097-1107, 1999.

21. Piazza GA, Rahm AK, Finn TS, Fryer BH, Li H, Stoumen AL, Pamukcu R and Ahnen DJ: Apoptosis primarily accounts for the growth-inhibitory properties of sulindac metabolites and involves a mechanism that is independent of cyclooxygenase inhibition, cell cycle arrest, and p53 induction. Cancer Res 57: 2452-2459, 1997.

22. Suhasini M, Li H, Lohmann SM, Boss GR and Pilz RB: CyclicGMP-dependent protein kinase inhibits the Ras/Mitogen-activated protein kinase pathway. Mol Cell Biol 18: 6983-6994, 1998.

23. Yamamoto Y, Yin MJ, Lin KM and Gaynor RB: Sulindac inhibits activation of the NF-kappaB pathway. J Biol Chem 274: 27307-27314, 1999. 